\title{
Harmonising seed regulatory regime for up-scaling global seed trade
}

\author{
Keshavulu Kunusoth and Pradeep Korishettar
}

Telangana State Seed E Organic Certification Authority, Hyderabad, India-500004

\section{Article history:}

Received: 25 July, 2021

Revised: 16 Aug., 2021

Accepted: 20 Aug., 2021

\section{Citation:}

Kunusoth K and P Korishettar. 2021. Harmonising seed regulatory regime for up-scaling global seed trade. Journal of Cereal Research 13 (Spl-1): 23-27. http://doi. org/10.25174/2582-2675/2021/115270

\section{"Corresponding author:}

E-mail: keshava_72@yahoo.com

\begin{abstract}
:
Quality seed of well adapted improved varieties are fundamental for the agricultural development. Considerable efforts have been made towards the strengthening seed sector in many parts of the world in terms of seed production and distribution with appropriate seed policies, laws and regulations etc. Global seed market is growing enormously and is highly dependent on the seed regulatory frameworks at national and international levels. An efficient and transparent seed regulatory system is crucial to ensure that farmers have timely access to high quality seed at an affordable price. The international seed regulatory framework consists of (i) seed certification schemes based on varietal identity and varietal purity (OECD and AOSCA); (ii) seed testing (ISTA, AOSA); (iii) phytosanitary measures (IPPC, WTO-SPS and NPPO); and the plant variety protection (UPOV or sui generis systems). The rapid growth in the volume of international seed trade has given rise to many challenges, of which, the need for harmonization of seed regulatory framework is of utmost importance. International organisations such as, the OECD, ISTA, AOSA, UPOV and IPPC have been involved in the development of uniform, standard and science-based seed regulatory framework and methodologies, which have been adopted by the governments and seed industries around the world. The harmonization of seed regulatory framework with appropriate seed policies, capacity building activities, and awareness creation among the farmers would certainly help to boost the global seed trade by assuring confidence about the quality, good coordination between the public-private stakeholders, increased transparency and reducing technical trade barriers. This would also improve the farmers access to quality seeds of well adapted crop varieties in all the regions of the world.
\end{abstract}

Keywords: Global seed trade, Harmonisation, Quality seed, Seed regulatory framework

\section{Introduction}

The biggest challenge of the $21^{\text {st }}$ century is to meet the challenges of food and nutritional security for the evergrowing population of the world (Anonymous, 2017). The global agriculture is under tremendous pressure to meet the future demand for food grains while responding to the vagaries of climate change, resource depletions, land degradations etc. Under these circumstances, the success of agriculture in terms of production and productivity is 
highly depends on access to good quality seed, which is fundamental and most vital for agricultural development. The quality seed being a carrier of new technology is inevitable, the remarkable developments have been made towards the strengthening seed sector in many parts of the world in terms of seed production and distribution with appropriate seed policies, laws and regulations to ensure farmers access to quality seeds of improved varieties.

Seed being a vital input in agriculture, having immense impact on the global economy with the greater influence on the global agricultural production and food security, several countries have realised the importance of using high-quality seeds of well adapted improved varieties, and making significant investment towards seed sector development, in terms infrastructure, technology, capacity building etc. In 2021, the global seed market size is being estimated to be valued at USD 63.0 billion, and is projected to reach USD 86.8 billion by 2026 with a CAGR of $6.6 \%$ (Anonymous, 2021).

Cereal crops like wheat, rice, corn etc. are projected to hold the largest seed market share as they constitute a major portion of the world food demand and important source of nutrients for the majority of population across the globe. The factors such as, raising demand for food grains, technological advancements and innovations, hybridization technology, GM crops, significant shift in farming practices, increased quality consciousness among the farmers etc. are driving the seed trade worldwide.

\section{Seed Regulatory Regime and Global Seed Trade:}

The global seed trade is highly dependent on the seed regulatory frameworks at national and international levels. An efficient and transparent seed regulatory system is crucial to ensure that farmers have timely access to high quality seed at an affordable price. The international seed regulatory framework consists of (i) seed certification systems based on varietal identity and varietal purity (OECD, AOSCA, EU Directives etc.); (ii) seed testing (ISTA, AOSA); (iii) phytosanitary measures (IPPC, WTOSPS \& NPPO); and the plant variety protection (UPOV or sui generis systems). The seed regulatory frameworks at regional level have also been developed to facilitate regional seed trade e.g. Central America, Mercosur, EAC, SADC, ECOWAS, etc (Joseph Cortes, 2009).

\subsection{Seed certification systems:}

Globally, there are mainly three systems for certification of seeds (i) the OECD Seed Schemes with 62 country members, it is a mandatory/compulsory system which provides benchmark for international seed trade, encourage the use of seed of high quality in participating countries with 8 broad groups of seeds, and authorize the use of labels and certificates for seed produced and processed for international trade; (ii) the AOSCA, which is a non-compulsory system, adopted in the countries like US, Canada, Argentina, Brazil, Chile, Australia, New Zealand and South Africa etc. It is the pioneer of modern-day seed certification in many of the nations including India. AOSCA promotes and facilitates the movement of seed in local, national, and international markets through the coordinated efforts of official seed certification agencies. It is also involved in the development of standards, regulations, procedures, and policies to expedite movement of seed and encourage international seed trade in coordination with OECD. (iii) The European Union (EU) is having a unified system of certification covering the whole region consisting of 27 member countries. The EU regulates the marketing of seed and propagating material of agricultural, vegetable, forest, fruit and ornamental species and vines for the whole region, which provides compulsory registration and certification (Singh \& Jain, 2014). Seed produced in countries other than EU may be marketed within the EU, if the seed affords the same assurances as seed officially certified within the EU i.e. EU seed equivalence.

In addition to the above systems, FAO's Quality Declared Seed System (QDS) is also being adopted by many of the nations, especially African nations. These guidelines/ protocols are aimed at assisting small-scale farmers, specialists in seed production, field agronomists and agricultural extension services in the production of quality seed. The system provides an alternative for seed quality assurance, particularly designed for countries with limited resources, which is less demanding than full seed quality control systems but yet guarantees a satisfactory level of seed quality (Anonymous, 2006).

\subsection{Seed testing:}

In the field of seed testing, the internationally agreed and standard rules for seed testing developed by ISTA and AOSA, are being referred around the world for facilitating 
seed trade. More specifically, the AOSA rules are being adopted mainly in North American countries and the ISTA rules have been adopted by majority of the countries around the world. However, there are many countries that are not the members of either ISTA or the AOSA; the seed testing in such countries is yet to be streamlined. The ISTA and AOSA have been working closely to expand the scope of seed testing in newer countries towards harmonised rules for seed testing.

Seed testing is a science of evaluating the planting value of seeds in terms genetic purity, physical purity, physiological purity, seed health etc. It is the corner stone of quality seed supply chain and plays a critical role in ensuring genuinity of seeds and preventing farmers from sowing low quality / substandard quality seeds, thereby protecting them from financial losses. The term quality seeds, from the perspectives of farmers, seed trader and regulatory bodies, is the seed that produces a healthy and vigorous crop, eventually give raise higher yields and better income. In a healthy and competitive seed market, the farmers must be enabled to compare the quality of available seeds. To facilitate this, all the essential information about the seed quality parameters must be made available on the seed containers. In this context, the science of Seed Testing plays an important role by providing the basis for seed trade in domestic as well as international market.

The concept of seed testing dates back to 1860 s when Professor Friedrich Nobbe advocated that seed must be tested before sowing in order to ensure the desired crop stand. Since then, considerable expansion and strengthening of the seed testing programmes have taken place at the global level. In the earlier days, there was no uniformity in seed testing procedures and so the variations in test results among the laboratories around the world.

\section{Standard Rules for Seed Testing}

Though the seed testing was in practice in the early $19^{\text {th }}$ century to provide information on the planting value of seed to the farmers and traders. However, there was no uniformity in seed testing procedures across the regions. Hence, the need for having harmonised and uniform rules and procedures for seed testing had arisen and that necessitated an in-depth knowledge of plant and seed morphology, taxonomy and physiology as a prerequisite for the development of harmonised seed testing methodologies, and also the research and development activities in different areas of seed science and technology. This led to the establishment of organisations like Association of Official Seed Analysts (AOSA) in 1908 and International Seed Testing Association (ISTA) in 1924, subsequently the standard rules and procedures for seed testing have been developed and since then they are being adopted by many countries for evaluation of quality of seeds moving in to the domestic and international trade.

\section{International Seed Testing Association (ISTA)}

The International Seed Testing Association was established in 1924 with the primary objective to develop, adopt, and publish standard procedures for seed sampling and testing and to promote uniform application of these rules for the evaluation of seeds moving in international trade. ISTA also promotes research in all aspects of seed science and technology, including sampling, testing, storing, processing, etc.; encourages cultivar certification; participates in conferences and training courses aimed at furthering these objectives; and establishes and maintains liaison with other organizations having common or related interests in seed testing.

At present, ISTA has 235 member laboratories in 82 countries. The technical and scientific work of the association is carried out by 20 technical committees. One of its foremost achievements was the adoption of the International Rules for Seed Testing. These prescribe testing techniques based on scientific evidence, which are accurate within stated statistical limits and practicable within the everyday operations of seed production, processing, and distribution (https://www.seedtest.org/ en/home.html). The International rules for seed testing published by ISTA have been adopted by the most of the countries. This ensures uniformity in seed quality testing and facilitates national and international seed trade, and also contributes to food security.

ISTA through its constantly evolving approaches has been making efforts at the international level in terms of standardization of methodologies and rules for seed testing, which have contributed significantly towards growth of international seed trade. Members of the ISTA are drawn from analytical or research laboratories in the public sector as well as from the private seed industries around the world. This position at the interface between research, industry and regulation greatly facilitates the 
development of new methods as per the needs of industry. In addition, the strong participation of the government representatives of distinguished economies as designated authorities, and close contacts with international organizations (such as ISF, AOSA / SCST, IPPC, FAO \& OECD) and regional organizations (such as AsiaPacific Seed Association, African Seed Trade Association, American Seed Trade Association etc.) play a major role in the strategic development of ISTA and its methods.

ISTA has been developing standard seed testing methodologies to facilitate the seed trade through its activities such as, identification and development of methodologies as per the changing needs of the industry; transparent programme for method validation; communication of the results in a standard and comprehensive international seed analysis certificates; promotion of uniform application of methods and the accreditation of laboratories; verifying the competence of laboratories through a global proficiency test program and dissemination of knowledge of seed testing through regular capacity building programmes. The methodologies and protocols developed by ISTA have been recognised globally for seed trade and adopted by the several countries around the world in their national seed regulatory frameworks.

\subsection{Phytosanitary measures:}

Seed being an internationally traded commodity, is considered high-risk material in international trade, providing a ready pathway for movement of pests, especially seed-borne pathogens. The phytosanitary regulations have been developed and adopted in accordance with the IPPC to prevent the spread and introduction of pests of plants and plant products and to promote appropriate measures for their control.

The International Plant Protection Convention (IPPC) is the international phytosanitary standard-setting organization, recognized in the World Trade Organization Agreement on the Application of Sanitary and Phytosanitary Measures. The International Standards for Phytosanitary Measures (ISPMs) published by the IPPC provide guidance regarding phytosanitary measures and their application to the international seed trade. Phytosanitary certification of seeds for export and compliant with importing country requirements remains a core obligation of Contracting Parties to the IPPC. Importing countries are obligated to require the application of measures that are consistent with the principles outlined by the IPPC.

\subsection{Plant variety protection laws / IPRs:}

In terms of plant variety protection, UPOV is the most widely recognized system for plant variety protection, and currently it has 74 members (https://www.upov. int/portal/index.html.en). Some of the countries have adopted the sui generis system of plant variety protection in accordance with the GATT, and in some countries the rules are ambiguous and yet to be streamlined.

\section{Conflict of Interest}

Authors declare that they have no conflict of interest.

\section{Ethical Compliance Statement}

NA

\section{Author's Contribution}

KK: Collection of literature, Conceptualization, Compilation, Writing original draft; PK: Final editing, Proof Reading

\section{Conclusion}

The seed trade is one of the most regulated areas around the world with suitable seed laws, testing methods, and certification processes. The rapid growth of international seed trade has given rise to many opportunities and challenges, of which, the need for harmonization of seed regulatory framework is of utmost importance and is a herculean task ahead. In the recent past, the considerable efforts have been made at the international level in the adoption of national, regional and international agreed standard seed certification measures. There are plenty of global examples of successful harmonisation of seed standards and certification processes, such as, the EU unified system of seed certification, FAO's efforts towards harmonisation of seed systems especially in developing countries, regional systems in Africa like Southern African Development Community (SADC), the Economic and Monetary Union of West Africa (UEMOA) and the Economic Community of West African States (ECOWAS). International organisations such as, the OECD, ISTA, AOSA, UPOV, IPPC have been involved in the development of uniform, standard and sciencebased seed regulatory framework and methodologies, which have been adopted by the governments and seed industries around the world as per their national 
requirements and has been greatly facilitating the growth of the global seed trade. For instance, the OECD / AOSCA Seed Certification Schemes and the ISTA seed testing methods have been embedded in seed laws and regulations of many countries and they are widely used by the seed industry throughout the world. In India also, the Government of India has adopted the ISTA rules for seed testing and AOSCA model of seed certification system, which are being used in national seed quality assurance system for ensuring quality seed supply to the farmers.

Despite the efforts of all the international organisations and treaties, still there is great variation in seed regulatory framework among the countries/regions. Seed certification is voluntary in few countries (North America) and mandatory in few countries (In various European countries), procedures, standards and seed classes differ from nation to nation, in few cases certification includes sampling \& testing and, in few cases, only field inspection and control plots. There is a lack uniformity in seed regulations, policies and phytosanitary requirements (except few cases) among the nations. This has been a major hurdle for seed trade between the regions/ countries. In this connection, the harmonization of seed regulatory framework, appropriate seed policies, capacity building activities, and awareness creation among the seed company would certainly help to boost the global seed trade by assuring confidence about the quality, good coordination between the public-private stakeholders, increased transparency and reducing technical trade barriers. This would not only encourage the growth in the seed trade but also improves the farmers access to quality seeds of well adapted crop varieties in all the regions of the world.

\section{References}

1. Anonymous. 2021. https://www.reportlinker.com/ p04436644/?utm_source=GNW

2. Anonymous. 2017. http://www.fao.org/3/i6583e/ i6583e.pdf

3. Anonymous. 2006. http://www.fao.org/3/a0503e/ a0503e00.pdf

4. Joseph Cortes. 2009. Overview of the regulatory framework in seed trade. Proceeding of the $2^{\text {nd }}$ World Seed Congress, held from September 8-9 at Rome, Italy. Pp 202-204.

5. Singh SP and N Jain. 2014. Harmonisation of Seed Certification Processes in Bangladesh and India. Published by CUTS Centre for International Trade, Economics \& Environment (CUTS CITEE), Jaipur 302016, India.

6. https://www.ippc.int

7. https://www.seedtest.org

8. https://www.upov.int 